\title{
The Ascent Within: Transformative Agency of the Nanda Devi in Bill Aitken's The Nanda Devi Affair
}

\author{
Arup Pal \\ Assistant Professor, Department of English, Visva-Bharati, Santiniketan. ORCID: oooo- \\ ooo1-9906-60o7 Email: arup.listens@gmail.com
}

\begin{abstract}
The Himalayas, it is commonly agreed, stupefy the traveler first by the immensity of the unknown and then elevate his journey by offering an almost unclimbable challenge-the imaginative recording of what is seen and felt. Overwhelmed by the accounts of numerous narratives, Bill Aitken, a Scottish-born-Indian in the early 196os, travelled from Calcutta (now Kolkata) to the Nanda Devi, once considered the highest Indian peak. He narrated his experiences in The Nanda Devi Affair (1994). In this journey, the text suggests, the climber's inbuilt intensity of life-from sheer physical pleasures to calm resignation-is tested. This study intends to explore how the altitude's transformative vigor allows the travelling subject to participate in "an interaction of the human and natural" (Bainbridge, 2016, p. 628), thereby offering a space in which the selfbefore-the-journey (pre-climb episteme) and the self-endowed with physical actuality negotiate a new understanding. The study offers an introspection on how the Nanda Devi helps the travelling identity realize a psychic evolution from the mere sensual excitement of a lured mountaineer to, what Aitken notes, "the elusive understanding of slippery psychic subtleties" (2004, p.189), thereby questioning and purifying the preconceived ideas of the traveler to achieve a sense of selfhood.
\end{abstract}

Keywords: The Nanda Devi, Mountain literature, Bill Aitken, The Himalayas, Interactive space

\section{Introduction}

The Himalayas, it is commonly agreed, stupefy the traveller first by the immensity of the unknown and then elevate his journey by offering an almost unclimbable challenge-the imaginative recording of what is seen and felt. Human incompetence to actualize mountains is famously expressed by Percy Bysshe Shelley in 1816 on his first visit to Mont Blanc: "I never knew-I never imagined what mountains were before" (Shelley and Shelley, 1817, p. 151). Such ignited limitation of the traveller's (heroic) experience of the mountain is similarly noted by numerous mountain-writers. The mountain, with its multifarious resources, excites the traveller's idea of pain and turmoil, and enables him to articulate his physical grounding from the aspect of pleasurable terror or terrible delight. In a journey, a Himalayan one in particular, there is a sense of surprise added to the excitement. It is because the Himalayas "alter the souls of even those who do not come to them, or behold them, as seekers" (Gokhale, 2016, p. xvi). In The Nanda Devi Affair (1994), Bill Aitken's pursuit from the intellectual terrain to the spiritual well-being comes after the sublime understanding when the height's physical buoyancy interacts with the human soul. Besides being a picturesque site, the mountain is a knowledge-maker, persistently-when in contact with-affecting its recipient to go through a self-reveling enquiry'. This search seems to be manifested when the traveller moves beyond the emotive and intellectual states and finds himself in and with the heights' natural openness. The mountain's situational loftiness, moreover, allows him to get rid of worldly sentiments and, in turn, accommodates the journey of the soul by

(c) AesthetixMS 2020. This Open Access article is published under a Creative Commons Attribution Non-Commercial 4.o International License (http://creativecommons.org/licenses/by-nc/4.o/), which permits non-commercial re-use, distribution, and reproduction in any medium, provided the original work is properly cited. For citation use the DOI. For commercial re-use, please contact editor@rupkatha.com. 
imbibing the eternal purity of this geo-physical height. It is then not surprising that such union between human and Nature enriches the travelling identity.

The present study is on mountain-travel, with specific reference to the Nanda Devi, once (erroneously) considered the highest Indian peak. My research findings rely primarily on Bill Aitken's The Nanda Devi Affair. Overwhelmed by numerous accounts, Bill Aitken, a Scottishborn-Indian in the early 196os, travels from Calcutta (now Kolkata) to the Nanda Devi, located in the present day Uttarakhand. The study attempts to explore how, in this journey, Aitken, notwithstanding his avowed interest in religion, acts more as an environmentalist, always concerned with the reservation of pahari customs and disappointed with callous mountaineering practice. It will focus on how a climber's inbuilt intensity of life-from sheer physical pleasures to calm resignation-is tested. It also intends to explore how the altitude's transformative vigour allows the travelling subject to participate in "an interaction of the human and natural" (Bainbridge, 2016, p. 628), thereby offering a space in which the self-before-the-journey (preclimb episteme) and the self endowed with physical actuality, negotiate a new understanding.

On the surface, Aitken travels to understand the unattainable mystery of the Himalayas, metaphorically he journeys for self-knowledge. Mountains allow liquidation of intensity and calmness. To understand the Nanda Devi is to understand the limits of human capabilities-to see beyond one's inhabited knowledge. Sometimes Aitken seems to hear, what Colin Thubron himself finds in To a Mountain in Tibet, his own "silence" (2012, p.10), while evaluating acknowledged idea with the unacknowledged one. Mountain's moral activity upon mountaineering teases the climber's freedom, liberates his self to become another, and finally infuses a sense of calmness in him. The traveller's act of becoming the mountain is, thus, ascertained.

\section{Mountains as Humane Urge: Altitude as Agency}

The inescapable urge of the climber to submit himself to the mountain comes from his belief that there is a sense of "brotherhood between man and mountains" (Aitken, 1994, p. 5). The altitude's physical extreme with added claustrophobia in tent, understandably, gratifies Aitken's growing sense of toil:

Perhaps this inbuilt intensity of life at higher altitude conditions rubs off on to the viewer. Looking up to the main peak in this sunnier season I found the peak bathed in a brilliant coppery dazzle with the bands of compacted granite appearing to glow with a green fire. The sober grey peak with its white striations had been the Devi's monsoon dress. Now in the translucent air of September her glossy greyness was overshone with a spectrum of soft colours that gave off that marvellous feel of the archetypal treasure at the end of a rainbow. [. . . ] The same sheer physical pleasure coursed through the observer at both seasons. It was an enormous privilege to have won through again to this sensuous theatre. (Aitken, 1994, p.86)

Aitken also realizes that "the propensity of many mountaineers to rip off whatever took their fancy as a souvenir had taught the more sober of porters to guard their cultural artifacts against the temptation of a quick sale"(p. 87). Invited by the altitude's human spirit, he leaves a handprinted visiting card of Radha and Krishna (the ultimate Hindu incarnation of self-sacrificial love) and wishes to see if this relic survives until his next return. Aitken, the devotee, is expecting his relic to be there against all natural and manmade calamities by surpassing human reasoning. It 
was almost as if, amidst Nature's benevolence and passage to meet the self, a willing suspension of surrealistic brilliance is formed.

Throughout the journey, Aitken is surprised by his porters' perseverance and loyalty. Their taking risk of carrying Aitken across is, to the travelling identity, a display of selflessness and inclusive attitude towards life. Aitken cannot resist himself expressing his heart out: "It was a heroic moment and I thumped him [Nathu] on the back in appreciation. It was not just the achievement of fulfilling a voluntary responsibility that impressed, but the inherent fighting qualities of a simple village thakur on display" (p. 55). Being practical, Aitken understands that it could have been otherwise had there been any lesser character in them. He adds: "It was this tremendous demonstration of loyalty that touched me most and I presented my watch to Nathu as a token of affection for his bigheartedness. It had been given to me by my guru and so would pass from one compassionate hand to another" (p. 55). The keen eye of Aitken hardly misses anything. The "hysterical" (p. 55) association with the indomitable natural phenomenon constantly reminds him of his insignificance and human incomprehensiveness reinforcing the idea that Nature is content in itself. Mountain climbing, essentially, makes one more compassionate, more liberating. Aitken seems to compare the paradoxical incongruity of Nanda Devi's ferocity and gentleness with the mountaineer's passionate intensity and spiritual oneness. The awarding experience on Aitken's part is written down uncompromisingly: "The experience, had I undertaken it just for altitude gained or a place in the record books might have missed out on the real trophy-the rare opportunity to learn more about the mystery of selfhood" (p. 57).

The altitude's hardship is not without surprises. After five days of wet marching in the month of July, the usually avoided season of monsoon for climbing, Aitken notices for the first time a patch of blue sky, giving his labour a momentary please. A sensation of sheer completion sets in as the travelling-self cheers at the regal sight of what he desires most until now:

It seemed a minor miracle that the sun should choose this moment to reward my labours. As the reluctant beauty of the mountain strove to outwit the parting cloud cover I was aware almost painfully of the strong erotic pull this peak of passion had on me. It was almost as if a spiritual striptease was being performed. I could only gape as the revelation neared its climax. [... ] There was a feeling of utter fulfillment and a song of thankfulness welled up from that core of contentment that follows the union of heaven and earth; the perfect end to all our striving. (Aitken, 1994, p. 52; emphasis mine).

Aitken is talking outside technological and strategical grounds tied with mountaineering energy. To him, human attainment for a greater height can also be a meditative practice for the attainment of the self. To him, it is more of summiteering one's inner spirit than of establishing one's human presence to something not easily available. Heights' transformative power, often unnoticeable, gives the alpine endeavour a certain structure by nurturing the traveller's momentary quest. Their locational uniqueness can afford the loftiest of thoughts. The allegorical attitude of ascension and descendance, elevation and downfall that the mountaineering literature can accommodate challenges, thereby, legitimizing the physical and psychological tussles of the climber. Owing to the interaction between the human and the natural at geophysical extreme, mountaineering, Simon Bainbridge (2016) opines, becomes "the site of revelation, a location for the selfs triumph or obliteration, the point beyond which further ascent becomes impossible but where communion with the divine seems imaginable"(p. 628). Having gone through different accounts, Bainbridge further notes: "While mountains are an inspiration for travel and travel writing, they also present particular challenges to those who seek to record them. A sense of the mountain's overwhelming, astonishing, or stupefying power was central to the cult of the sublime 
[. . .]" (p. 628). Transformation is ineluctable in mountaineering because "[a]scent produces transformation and individual aggrandisement, though the elevated state can only be registered through definition against the grub-like state of ground-level existence" (p. 637). It is also because climbing distances the travelling identity from his previous existence and makes him a conveyer of immense possibilities, thereby setting a symbolic challenge to his growing-up self.

\section{Devi-Darshan: The Idea of Femininity in the Nanda Devi}

The Nanda Devi, with the revealing self's romantic attachment, as regal-a queen with necklace, seems to have mesmerized Aitken's sensory applaud by her individuality of being so physically attractive yet distant:

Nanda Devi tops the scene at $25,645 \mathrm{ft}$ (7.817 metres) serenely aloof and set back apparently from the company of her courtiers. It took me twenty years to prise out the secret of her innermost lair and those who see only the outer majesty of the mountain would find it hard to apprehend the magic of her hidden fastness (Aitken, 1994, pp.7-8).

We are already informed that the drama and interplay associated with the extraordinary direct spectacles of the Nanda Devi is better disclosed when the sight is partly-clouded. In his darshan(s) (which may be translated as sacred perception), the Nanda Devi turns from "bliss-giving Goddess"(p. 15), "Hindu garden of Eden"(p. 15) and "patron Goddess of both Kumaon and Garhwal"(p. 2o) to a guardian spirit. Aitken's tie with the Nanda Devi is layered: the Nanda Devi is at once a maiden delight and an awe-inspiring Goddess, metamorphosing his sensual evocation to inner ecstasy. Aitken, almost becoming a mountain mystic, observes that the Nanda Devi's unavoidable grace-as a common mediator-mellows down the long feud between Kuamon and Garhwal-the two rival cultural provinces distinguished by their dialects and customs (p. 20). The critic in him finds the rendering by some Almora pundits erroneous: "Some Almora pundits hold that "the hump of the main peak proves that Nanda is a corruption of Nandi the bull, sacred vehicle of Shiva. They argue that rather than a Goddess the mountain is the footstool of Shiva who dwells on Kailash"(p. 121). From a physical proximity, however, Aitken presents a practically un-dismissing argument. By refuting that Nanda Devi is "the outer guardian of Shiva's holy mount Kailash"(p. 22), he questions the pundits' assumption by highlighting Nanda Devi's exceeding the height of Mt. Kailash by some three thousand feet. Aitken's cultural nearness and geographical knowledge makes his hold more assertive. His abiding interest in religion and mutual affinity with Mussoorie-based Prithwi in exploring the pilgrim sites of dev-bhumi, encourages him to overcome the "strains"(p. 29) that arise when East and West come in contact with each other.

Aitken, however, is aware of the British misnomer by the title 'Kumaon Himalaya,' in order to, the traveller reminds us, "confuse the primacy of Garhwal”(p. 20):

To Hindu hillmen 'Kumaon Himalaya' instead of Uttarakhand was a gratuitous insult and to students of geography it became a baffling riddle that gave rise to hilarious assumptions totally at variance with ground realities. The worst victims were mountaineers in transit who, ignorant of the Wars of Roses situation that holds between Kumaonis and Garhwalis, failed to understand that this usage to a Garhwali is like describing Lancashire as part of Greater Yorkshire or Havard as an outpost of Yale.(p. 21)

While contemplating the religio-cultural rigour of Kumaon, Aitken sympathy with the local suspicion of him being a spy or police informer is not unjustified. His physical intimacy, moreover, of the dailyness of the Garhwali livelihood intervenes with his present understanding, 
first as a tourist, and secondly as an ecologist. His lingering eye holds the sight of uncomplaining acceptance vis-à-vis extremes of Nature. His admiration of Garhwali women, hardly talked of in conventional hill narratives, comes from his several firsthand experiences:

One of the Kausani [a small town in present-day Uttarakhand] wardens claimed to have had a close encounter with a bear while cutting grass. The animal had got her in a close embrace but instead of screaming the woman had faced her molester and bravely tapped her sickle on the bear's chest to indicate a counter threat. The bear, unaccustomed to a non-wriggling victim and puzzled by the insistent tapping, let go of her. It might be added that the woman was a hardly Bhotia who though not technically beautiful enough for a bear to lust after, was such an extraordinary character that her story seemed perfectly credible. (p. 32)

In the text, it is also found that Aitken's personal interest is deepened in contact with the villagers' simple, calm and physically challenging lifestyle. Having the knowledge of different representative variances, his narrative finds in the Nanda Devi a fine convergence of the mountain Durga (the Hindu Goddess of light and truth) in terms of 'shakti' (strength) and beauty, and Swaraswati (the Goddess of knowledge and one incarnation of Durga). Aitken's exploration does not merely reveal a traveller's interpretative erudition but also a man's submission to his beloved: "It was hardly surprising that in my own choice of physical partner I should have chosen a woman who combined the fiery power of Durga with the devotional instincts of Saraswati [Swaraswati]" (p. 28). The Nanda Devi, "the stimulator of self-consciousness" (p. 37), is therefore the leveller of religio-cultural differences:

[. . . N Nanda Devi transcends the sectarian loyalties of the orthodox to include the tantrics as well as gather in the vote of the aboriginal outcaste. Alone in Uttarakhand the Goddess soars above the differences of dress and language, custom and diet. This ability to ennoble the primitive strivings of hill society make the peak an object of reverence as well as a fascinating study in the power of religion to integrate warring parts. Devotion for the Devi flowers 'barah masah' [literally, twelve months] —all the year round. (p. 38)

At his first darshan, Aitken is overwhelmed by "the union of heaven and earth," and considers it appetizingly fulfilled (p. 52). After overcoming the physical odds, faced while taking risk of venturing into Nanda sanctuary, he focuses on the tribal practice of worshipping the Devi through crude sacrificial behaviours. The animality may be considered to be more primitive, but its sacrificial nature implies the native courage and loyalty.

Unlike W. H. Tilman's masculine interest in considering the feminine Nanda Devi by summiting its peak in 1936, Aitken's failure or disinterest both at the physical and metaphoric grounds leads his narrative beyond a gendered reading of feminization. Rather, his account exemplifies human knowability about the Nanda Devi's endless resources. His travel philosophises human realization in the high plateau of knowing the other. His initial consideration of the Nanda Devi as an alluring female figure and consequently his revelation to find in her a 'guru' on whom a male figure can depend, associate and purge of physical longings so as to find a spiritual height establishes the growth of his travelling identity. The implication that the mountain offers one space to aspire, inspire, introspect is entailed throughout Aitken's quest for the finer meaning of existence. Nan Shepherd's metaphysical meditation seems to justify Aitken's spiritual height: "The body is not made negligible, but paramount. Flesh is not annihilated but fulfilled. One is not bodiless, but essential body" (Shepherd, 2011, 83). 


\section{The Transformative Traveller}

The Gandhian ashram where Aitken worked as a part-timer enabled him "to get into the slow rhythm so necessary for a foreigner who hopes to become part of India" (Aitken, 2003, p. 8), and it was the Mirtola ashram which helped him to "unlearn" so many things in life (Aitken, 2003, p. 2). The ashram experience led Aitken to a yogic understanding for over sixteen years. Impressed by the ashram culture of renunciation and love, he comes closer to the idea of Indian inclusivenessit is here his interest in consuming foods is mellowed down by spiritual thirst. Ascension gives him wisdom for resting unrealistic ambition and helps him rationalize his thoughts. As a conveyer of stimulating thoughts now, he seems to sense the mysterious vastness of the mountain. He senses that this limitlessness, too, echoes human vastitude lying inside and often undiscovered. Observing is also sensing; understanding generates participation; participation is impossible without widening one's interests and "the essential unquenchable joy of life" (Aitken, 2003, p. 35) usually unspoken of.

Aitken's understanding of the Nanda Devi does not limit itself as mere expedition of a mountaineer. The traveller in him rather tries to decipher the cultural and historical engagements with this mountain. Based on the general consensus, which holds that the first ascent of the Nanda Devi was accomplished in 1935 by an Anglo-American troop, Aitken presents its impact on Garhwal livelihood:

[ . . ] village custom was outraged when it heard that mortals had stood atop the sacred summit, defiling the gold pavilion of Vishnu [the Hindu God of ????] with their boots. On the day of the first ascent-August 30-Garhwal experienced a cloud-burst and the hill station of Mussoorie reeled under eighteen inches of rain. In the village of Tharali the Pindar river, rising in the eastern flank of the mountain, drowned twenty men and it was widely believed that this reflected the anger of Nanda Bhagawati (as hillmen call their protective deity). (Aitken, 1994, p. 12)

To Aitken, the logical justification of how a Himalayan peak could become a protective deity surpasses into faith. It is likely that his faith rests with the abiding faith of the Garhwal community. Going against the foreign summiteers, who find religo-cultural intimacy with the Himalayan climbing irrelevant and almost always ignorant of the Nanda Devi's impact on them despite their assumed details of climbing passage, Aitken points out that it is difficult to overlook the "uplifting terrain"(p. 13) closely intertwined with the folklore of popular Hinduism.

The enormity of the mountain is further felt when, in a mild but sudden earthquake, the travelling identity rationalizes human ephemerality. Aitken's mystical association with the increasing knowledge of the Himalayas is better explained as he says: "the great mountain views do not lie only in the physical meeting of the coordinates. By depriving me of the wonder of Changabang's upthrust glory the Goddess had forced me to question whether I could live without capturing the peak on camera. Or would I die forever unfulfilled, with 'Changabang' engraved on my heart?"(p. 7o). He then goes on to respond to his own queries:

The answer that has come slowly, painfully and platonically is that Changabang is but a reflection of the true mountain within. Of course the external beauty is real and its outer form sacred but all reality arises from the same source as our sense of wonder. Here is the paradox of our condition. How to unite inner and outer perceptions? Nanda Devi speaks to both states for she is the source of wonder springing in the heart of those who love her; enlarging our individual perceptions until they include all opposites. (p. 70) 
Aitken's narrative subtly leads the reader's attention to the traditional, ritualistic overhearing that the Nanda Devi holds. As a culture-sensitive traveller, he is not unaware of the folklore entwined with the sacred Nanda Devi darshan. Referring to the human tragedy of Rup Kund, a mysterious lake in the lap of Himalaya, he muses on how a medieval king along with his men enraged the Devi by their behaviour to perform a pilgrimage in serenity and received fatal wound. The commentator in Aitken warns us against the romanticized Himalayan-climbing callousness of some mountaineers. He mirrors how the heroic ventures of leader climbers turn to "a farcical descent that resulted in the death of a climber and serious frost-bite injuries to his companions"(p.103). He seems to suggest that the Himalaya allows no wrong move. Hill climbing, in fact, makes the climber vulnerable, by testing his nerve, then surprises him, with inexpressible delight.

As an environmentalist, Aitken's effort to question any kind of commodification of the mountain culture cannot be overlooked. This is because, for him, the mountain provides an inspiring zone for living and sensing. As far as reaching the peak is concerned, it may only offer a momentary ego-boost, and surpass the climber's urge to meet, negotiate and overcome human limits. This feeling might be endemic to the act of climbing, as seen in the 1935 account Climbing Days, where mountaineer Dorothy Pilley untangles her trekking self by holding "how the sense cleared, [and] the self released" on the journey itself (Pilley, 1935, p. 2). It is more likely that Aitken's journey to the Nanda Devi largely rests to introspect the meaning of travel itself. His evocative description of the Nanda Devi may often turn out to be literal, but describing mountain as extravagant improbabilities connotes the idea of liberating oneself. Nan Shepherd's celebratory account echoes Aitken's philosophical understanding:

I believe that I now understand in some small measure why the Buddhist goes on a pilgrimage to a mountain. The journey is itself part of the technique but which the god is sought, it is a journey into being; for as I penetrate more deeply into the mountain's life, I penetrate also into my own. For an hour I am beyond desire. It is not ecstasy that leaps out of the self that makes man like a god. I am not out of myself, but in myself. I am. To know Being, this is the final grace accord from the mountain. (Shepherd, 2011, p. 108)

Aitken's visionary act of narrating the grace of Nanda Devi is, in turn, an inculcation of the overall summiteering experience, for, the writing self in sanctuary is not without the effect of ascension.

The physical strains from the lower slopes to the upper and vice-versa, the atmospheric uncertainty leading them to take shelter in the dark cave for an unspecified time, the seasonal hazards, bodily dysfunctions, altitude's abortive trek, inadequacy of food, psychological toil, the daring search for comfort in hostile conditions in order to avoid cold sleepless night, visiting the Nanda Devi temple for blessings for safe return, and above all, the submission of ego comprise of the traveller's seeking of the self. The traveller is now a seeker of truth, to be fulfilled by his happiness and hardships, success and failures. Aitken's approach is almost like a yogi to the Devi, who runs through a maddening physical desire but reaches with a mystical fulfillment:

Up here was true freedom. The worldly search ended in the dissatisfaction of stored-up funds the body could not enjoy. [. . . ] Here on these transcendentally lovely fields of the Goddess one was aware of the limitations of the intellect to embrace the truth of the moment. Only love could penetrate the essential spontaneity of the witnessing self. And one agreed [...] that death is not too high a price for a life lived fully" (p. 145). 


\section{Conclusion: Becoming a Mountain and a Sense of Selfhood}

Aitken's ceaseless search for the mystery of the presence of the Nanda Devi is quasi-satiated, and hence truer to a sense of selfhood-never complete, yet fulfilling in its fragments. In this pursuit, the change "from the masculine mental demands for black and white reasoning to the elusive understanding of slippery psychic subtleties" (p. 189) is viable. His understanding that life is foreign to mountains comes with his immediate knowledge of total trust that "exists between the climber and the rock he rests against"(p. 190). Between the climber's well-managed force to climb and the peaks' fierce forces, lies the adventurous rawness: "There is a profound truth in the unconquerability of the human will but its proper harnessing has been prevented by a Semitic distortion" (p. 191). Aitken deepens his argument in conversational pattern:

It was somewhere between the literal physical actuality of the peak and its religiosymbolic mystique (that includes the sporting appeal with its octausend magic) that the answer to my quest to identify the Devi lay. The peak was only as real as my passion for it. Those profound delights of nature so hardly won by financial and bodily suffering were not exclusive to the outer sanctuary but part of the wilderness we all have inside ourselves. (p. 191)

He confesses that his mountaineering is not a mad pursuit to reach the peak, but a journey that accords a context for introspection. Going beyond the idea of conquering the summit, the travelling identity absorbs, what Stephen Alter also finds, "the lofty knowledge of a mountain's presence while at the same time allowing ourselves to be absorbed into a greater awareness of what it may or may not represent"(Alter, 2014, p. 41). Aitken considers this awareness magical, and senses that the presence of flesh is, as if, mocked by the divine presence of mountain, an incarnation of Nature:

The mountain was a trigger to my soul, its arrival on the horizon a kind of heavenly descent that liberated my heart from the thrall of the intellect. Together animal and spiritual instincts came close to a rare union of nirvana. [. . .] The exclusion of the inhibiting mind and its analytical faculty worked to make one momentarily a child of the cosmos, intoxicated by the wonder of being, a small but significant part of this miraculous garment [. . . ](Aitken, 1994, p. 192)

From a sensual female figure in the Nanda Devi to the traveller's desperate search for a female guru for developing his underdeveloped intuition is now perceived. Overcoming his ego, Aitken's unconditional submission to the mountain's allegorical power is an act of purging himself of outer physical conditions and going with inmost instincts. His physical proximity to the Nanda Devi also results in his psychic nearness. As he now worships the Devi, he is, as if transcending all worldly concerns in a space of nirvana, part of the aura of the Devi. Devi, too, signifies the human side-the suppressed truth behind a façade of sensual joy. Overreaching the apparent remoteness between the outer and the inner, the spirit and the flesh, the traveller in Atiken holds that we are the conveyer of convergence-the creator of oneness.

Aitken is speaking outside technological/strategical grounds tied with mountaineering energy. To him, human attainment for a greater height can also be a meditative practice for the attainment of the self. He seems to believe that it is more of summiteering one's inner spirit than of establishing one's outer physical presence. The Nanda Devi, a site of self-knowledge, renders fascinating (impartial) uncertainty that mountains generate and subsequently transform the traveller to agree with the horror endowed with. In such communion, Aitken's experience of Nanda Devi rests outside leisurely pursuit, and goes beyond the rapturous joy in definite terms. A 
departure from quotidian normalcy/complacency, Aitken's communication of the extreme change of heights does not merely tantalize the reader but makes his account a sustained, albeit a nuanced romance, thereby making the traveller physically more enduring through intellectual and emotional toil. His earlier position of visitation now negotiates with his gradual growth with the intimate spaces of Garhwal Himalaya. The mountain's accumulative zone, in fact, helps him inculcate the depth of enormity and wonder. Amidst this, the Nanda Devi helps the travelling identity realize a psychic evolution from the mere sensual excitement of a lured mountaineer to the appreciation of slippery psychic subtleties, thereby questioning and purifying the preconceived ideas of the traveller to achieve a sense of selfhood.

\footnotetext{
Note

${ }^{\mathrm{i}}$ Amrita Dhar in her essay finds that among the many purposes of mountain travel, "the quest for encounter with the self" stands out prominently. For more, see "Travel and Mountains," 2019, p.347.
}

\section{References}

Aitken, B. (1994). The Nanda Devi Affair. Gurgaon: Penguin.

---. (2003). Footloose in the Himalaya. Ranikhet: Permanent Black.

Alter, S. (2014). Becoming a Mountain: Himalayan Journeys in Search of the Sacred and the Sublime. New Delhi: Aleph.

Bainbridge, S. (2016). “Mountains.” In C. Thompson (Ed.). The Routledge Companion to Travel Writing (pp. 628-41). New York: Routledge.

Dhar, A. (2019). "Travel and Mountains." In N. Das and T. Youngs (Eds.). The Cambridge History of Travel Writing (pp. 345-6o). New York: Cambridge UP.

Gokhale, N. (2016). “Introduction.” In R. Bond and N. Gokhale (Eds.). Himalaya: Adventures, Meditations, Life (pp. xiv-xviii). New Delhi: Speaking Tiger.

Pilley, D. (1935). Climbing Days. London: G. Bell and Sons.

Shelley, M. and Shelley, P.B. (1817). History of a Six Weeks' Tour. London: T. Hookham.

Shepherd, Nan. (2011). The Living Mountain: A Celebration of the Cairngorm Mountains of Scotland. Edinburgh: Canongate.

Thubron, C. (2012). To a Mountain in Tibet. London: Vintage Books.

Tilman, W.H. (2003). The Seven Mountain-Travel Books. London: Baton Wicks. 